\title{
Redes temáticas na web e biossociabilidade online ${ }^{1}$
}

\begin{abstract}
RESUMO
Este artigo trata da socialização online em blogs de pessoas com deficiência auditiva e de "informados" sobre o tema (Goffman, 1988), buscando identificar seu processo de Inclusão Social (IS). Na medida em que, nesta rede, os deficientes auditivos também são autores de blogs, considerou-se pertinente investigar o conceito de biossociabilidade (Rabinow, 2002; Ortega, 2008), assim como a questão do estigma (Goffman, 1988). Frente a isso, nota-se que o conceito de redes temáticas na web (Montardo; Passerino, 2008) se aplica apenas parcialmente a uma rede como esta, visto que os assuntos tratados na mesma compreendem, mas ultrapassam a questão da deficiência auditiva. Para viabilizar metodologicamente este estudo, a netnografia é utilizada para a identificação, seleção e obtenção de dados dos blogs selecionados, e, após, a Análise de Redes Sociais (Recuero, 2005) permite a análise das trocas empreendidas na mesma.
\end{abstract}

\section{PALAVRAS-CHAVE}

Biossociabilidade

Blogs

Redes temáticas na web

\begin{abstract}
This article discusses online socialization in deaf people's blogs as well as in blogs of people informed about this issue (Goffman, 1988). The aim is to identify its process of Social Inclusion. Once deaf people are blogs authors, we consider the biosociability concept a relevant point, just like the stigma question. (Goffman, 1988). Thus, we notice that the concept of thematic net on the web (Montardo; Passerino, 2008) is only partally apllied to a net like this one, because the subjects approached on it comprehend deafness, but also overpass it. To make this study methodologically possible, netnography (Hine, 2005, Kozinets, 2002) is used for identifying, selection and getting data from the chosen blogs. After that, Social Net Analysis (Recuero, 2005) allows the analysis of exchanges undertaken on this research.
\end{abstract}

\section{KEYWORDS}

Biosociability

Blogs

Thematic nets on the web

\section{Sandra Portella Montardo}

Professora do Programa de Pós-Graduação em Processos e Manifestações Culturais da FEEVALE/RS/BR.

sandramontardo@feevale.br 
Verificar como se dá a inclusão social (IS) ${ }^{2}$ de pessoas com deficiência e de seus familiares em redes sociais na web e, posteriormente, identificar padrões de socialização estabelecidos nestas redes, é o objetivo do projeto Inclusão social via socialização online de Pessoas com Necessidades Especiais (PNE) $)^{3}$.

Quanto à análise de blogs de pessoas com deficiência auditiva, pergunta-se: que padrão de socialização se percebe quando as próprias pessoas com deficiência atuam diretamente em redes sociais na web? Que limites e possibilidades os blogs, como suporte de socialização online, representam para pessoas cuja deficiência é auditiva? Em que medida pode-se usar o conceito de biossociabilidade (Ortega, 2008; Rabinow, 2002) para compreendê-la? E que implicação o estigma (Goffman, 1988) pode ter nessa abordagem? O conceito de rede temática na web se aplica a essa rede? Partindo-se desses questionamentos, e observando-se as delimitações impostas pelas opções metodológicas que guiam este artigo, como se dá a IS em blogs de deficientes auditivos? É fundamental, então, que se observem as características da deficiência auditiva para relacioná-las com as competências exigidas para a socialização online em blogs.

\section{Deficiência auditiva e estigma}

Deficiência auditiva ou surdez ocorrem quando problemas em alguma das partes do ouvido (ouvido externo, ouvido interno ou ouvido médio) prejudicam a audição em algum grau (Redondo; Carvalho, 2000).

Um ponto fundamental para identificar o padrão de socialização online de surdos é entender como ele adquire a linguagem necessária para se escrever em blogs. Seguem alguns métodos existentes:

a) Oralismo: consiste em fazer a pessoa sur$\mathrm{da}^{4}$ a ouvir e a falar. Para tanto, e com o auxílio de equipamentos, "o método começa com o treinamento de atenção para a leitura orofacial e inclui elementos sonoros isolados, combinações de sons e palavras e finalmente fala" (Moura, 2000, p. 53), requerendo o envolvimento da família para o pleno desenvolvimento da criança. Se necessário, complementa-se a prática com método oral unissensorial (ênfase na audição com aparelhos auditivos, sem utilizar a leitura labial nem a língua de sinais) ou o método oral multissensorial (estimula to- dos os sentidos: audição - com aparelhos auditivos -, visão - leitura labial -, e tato, etc.; não utiliza a linguagem de sinais) (Redondo; Carvalho, 2000).

b) Língua de Sinais (LS): dado os resultados insatisfatórios do método oralista, os estudos de Stokoe (1960), nos Estados Unidos, sobre a LS,

tanto no nível de sua estruturação interna como de sua gramática, provaram que ela tinha valor lingüístico semelhante ao das línguas orais e que cumpria as mesmas funções, com possibilidades de expressão em qualquer nível de abstração (Moura, 2000, p. 56).

c) Comunicação Total: considerada uma filosofia e não apenas um método, consiste em utilizar todos os meios possíveis para a educação dos surdos: "oralização, prótese auditiva, gestos naturais, linguagem de sinais, expressão facial, alfabeto digital, leitura labial, leitura da escrita, [...]" (Corrêa apud Redondo; Carvalho, 2000, p. 27).

d) Bilinguismo: congrega a LS e a oral (português), sem que uma interfira na outra, sendo úteis para situações diferentes (Redondo; Carvalho, 2000).

Moura (2000) destaca que a LS continua a não ser reconhecida, sendo que apenas a escrita é considerada a verdadeira fonte de acesso à linguagem. No entanto, como a autora faz notar, onde houver surdos haverá a LS. Desde o século XIX, o surdo se sente discriminado, sem direito à sua própria língua. De acordo com Moura (2000), a educação baseada na LS colaboraria para que os surdos fossem vistos mais pela sua diferença do que pela sua deficiência, posicionando-se na sociedade não pela sua exclusão em relação a ela, mas por meio de uma identidade definida em sua positividade.

\section{Um traço característico não é bom nem mau, sendo que o estigma, configurado como fator depreciativo, existe a partir da relação entre atributo e estereótipo.}

Na medida em que se trata de relações sociais envolvendo pessoas com deficiência auditiva, vale considerar as questões levantadas por Goffman (1988) sobre o estigma ${ }^{5}$. O estigma implica uma relação social, consistindo em um rótulo depreciativo que uma pessoa ou grupo atribui a 
outra pessoa ou grupo, com a finalidade de deteriorar sua identidade. Para o autor (1988), o estigma se revela na discrepância entre identidade social virtual (imputação de características a uma pessoa baseada em expectativas prévias) e a identidade social real (atributos que a pessoa realmente possui). Ou seja, por si só um traço característico não é bom nem mau, sendo que o estigma, configurado como fator depreciativo, existe a partir da relação entre atributo e estereótipo. Nas palavras de Goffman (1988),

o normal e o estigmatizado não são pessoas, e sim perspectivas que são geradas em situações sociais durante os contatos mistos, em virtude de normas não cumpridas que provavelmente atuam sobre o encontro (Goffman, 1988, p. 148-149).

Escolas residenciais, clubes, festas e competições esportivas que reúnam surdos são consideradas por Mottez (1999), citada por Moura (2000), como lugares que podem servir para estabelecer uma comunidade de Surdos. Nessa situação, a pessoa nunca vai ter a surdez como instrumento de discriminação contra si, posicionando-se socialmente sem o esforço requerido na presença de ouvintes, o que vai colaborar para a estruturação positiva de sua identidade. A cultura dos surdos, segundo Goggin e Newell (2003, p. 26), consiste em: "pessoas que nascem ou se tornam surdas, usam linguagem de sinais como sua primeira língua, e identificam a si mesmos como sendo surdos enquanto também participam de atividades dentro da comunidade".

Quanto a isso, Goffman (1988) faz uma leitura mais complexa. Se por um lado situações sociais mistas, em que as pessoas estigmatizadas e as ditas normais convivem, podem resultar em uma interação angustiada para ambas as partes, tal como pontuou Moura (2000), entre seus iguais há a possibilidade de os estigmatizados fazerem de sua "desvantagem" a base para organizar sua vida e, assim, concordarem com a resignação de viver de um modo incompleto. O autor (1988) destaca uma certa ambivalência quanto aos modelos de identidade adquiridos pelo sujeito estigmatizado, já que este não consegue se conformar a eles. Assim, um deficiente auditivo não se vê como surdo, nem o deficiente visual, como cego. É, portanto, na associação com os iguais, ou perante a separação deles, que haverá oscilações de identificação.
Quanto aos alinhamentos intragrupais dos estigmatizados, Goffman (1988) menciona os grupos dos "companheiros de sofrimento", cujos arautos defendem que o grupo verdadeiro, "natural" da pessoa com deficiência, por exemplo, é esse. Portanto, o indivíduo será uma pessoa "leal e autêntica" se se voltar para seu grupo; caso contrário, será "covarde e insensato", segundo o autor. Nesse contexto, identifica-se uma postura de militância, da qual se presume que quanto mais o grupo se afasta da sociedade a qual desdenha, devido às noções de orgulho, dignidade e independência inerentes a ela, mais eles se tornam parecidos com a mesma. Nesse tipo de alinhamento, a linguagem é política, como mostra Goffman (1988) e concorda Moura (2000). Segundo Moura (2000, p. 13), o Movimento Surdo centra-se na busca pelo seu "direito como cidadãos, as suas reivindicações sociais e políticas de educação e de trabalho [...]", além de sua inserção na Educação de outros surdos, prevendo-se bem mais de que uma simples "adaptação" ao mundo ouvinte.

Um deficiente auditivo não se vê como surdo, nem o deficiente visual, como cego. É, portanto, na associação com os iguais, ou perante a separação deles, que haverá oscilações de identificação.

Já os alinhamentos exogrupais, para Goffman (1988), exigem que o indivíduo estigmatizado se veja como normal, sendo que os discursos dessas relações têm base psiquiátrica. Para tanto, cabe ao estigmatizado entender o despreparo dos normais para com o seu traço distintivo, assim como "quebrar o gelo" quanto a ele em situações sociais.

De acordo com essa perspectiva parece estar o exemplo trazido por Goggin e Newell (2003), que mencionam "os desafios éticos" do Implante Coclear ${ }^{6}$ junto à cultura dos surdos. Para alguns, a cirurgia, que é recomendada para pessoas com perda profunda ou total de audição, e restaura sua audição, é considerada antiética por consistir no emparelhamento do surdo com um ponto de vista do mundo ouvinte, que tende a seguir o discurso médico sobre a deficiência, enfatizando a incapacidade. Na busca pela web sobre blogs de deficientes auditivos, foram encontrados seis que 
trazem relatos da experiência de passar a ouvir devido à cirurgia, além de um fórum específico sobre o Implante Coclear. Um deles foi analisado nesta pesquisa. Em outro, uma surda lamenta a posição dominante da Cultura Surda de ser contra a cirurgia. O conceito de blogs e sua possível relação com redes temáticas na web e biossociabilidade devem ser retomados para que esta análise seja feita.

\section{Blogs, redes temáticas na web e biossociabilidade}

Conforme Blood (2000), Jorn Barger utilizou o termo weblog em 1997, para nomear um conjunto de sites que "colecionavam" e divulgavam links interessantes na web. O surgimento e a evolução das ferramentas de publicação, a partir de 1999, popularizaram os weblogs, proporcionando uma maior facilidade na publicação e manutenção dos sites, que não mais exigiam o conhecimento da linguagem HTML. Devido a isso, passaram a ser rapidamente adotados e apropriados para os mais diversos usos. A ferramenta de comentários foi agregada mais tarde, e pode-se dizer que ela constitui hoje uma das principais características estruturais dos blogs por possibilitar a interação de leitores de blogs com os seus autores (Amaral; Montardo; Recuero, 2008).

Amaral, Montardo e Recuero (2008) sugerem que há três formas de se conceituar blogs: estrutural (descreve sua estrutura de publicação, como postagens e comentários), funcional (enfatiza suas funções de comunicação e de socialização) e artefato cultural (visto como um depositório vivo de experiências humanas).

\section{0 surgimento e a evolução das ferramentas de publicação, a partir de 1999, popularizaram os weblogs, proporcionando uma maior facilidade na publicação e manutenção dos sites, que não mais exigiam o conhecimento da linguagem HTML.}

Como destacam Bruns e Jacobs (2007) e Amaral, Montardo e Recuero (2008), observa-se a utilização dos blogs para diversos fins. Pode-se dizer que todas essas apropriações têm em comum o fato de permitirem a socialização online entre autores e leitores de blogs, por meio das postagens e dos comentários.
Em estudos anteriores (Montardo; Passerino, 2008; Montardo, 2008), conceituou-se rede temática como uma rede social na web, portanto como um conjunto de nós e de suas conexões (Recuero, 2005) que se estrutura em torno de um tema específico e que se mantém restrita a ele. Cabe verificar se esse conceito se aplica a uma rede em que os próprios autores têm a deficiência auditiva, mas não sem antes investigar sua relação com a biossociabilidade.

Em pesquisa focada na articulação de discursos e práticas do biopoder a partir de um estudo etnográfico do Projeto Genoma, mas que não se restringe a ele, Rabinow (2002), busca verificar as mudanças de práticas e éticas no decorrer do avanço desses estudos. Biopoder, para Foucault (1984) é "aquilo que faz com que a vida e seus mecanismos entrem no domínio dos cálculos explícitos e faz do poder-saber um agente de transformação da vida humana" (Foucault apud Rabinow, 2002, p. 135). Ortega (2008) destaca que o biopoder se articula de uma dupla forma: 1) anátomo-política do corpo, via disciplinamento corporal; 2) biopolítica das populações, cujo objetivo era a medicalização e a normalização da sociedade. O argumento de Rabinow (2002) reside em que corpo e população estejam em vias de se rearticularem no que ele chama de racionalidade pós-disciplinar, uma vez que a nova genética converter-se-á em um fluxo de termos de identidade e lugares de restrição, por meio da qual surgirá a biossociabilidade. $\mathrm{O}$ contraste abaixo esclarece o conceito:

Se a sociobiologia é cultura construída com base numa metáfora da natureza, então na biossociabilidade a natureza será modelada na cultura compreendida como prática: ela será conhecida e refeita através da técnica, a natureza finalmente se tornará artificial, exatamente como a cultura se tornou natural. Se este projeto chegasse a ser realizado, ele seria a base para superar a separação entre natureza e cultura (Rabinow, 2002, p. 143-144).

O autor (2002) cita Castel quanto à dissolução do social nas sociedades ocidentais ser condição sine qua non para que essa superação ocorra, na medida em que o biológico passa a atuar como fator determinante do cultural. Entre as várias questões subjacentes às possibilidades do esquadrinhamento genético, Rabinow (2002) destaca a formação de novas identidades e práticas individuais e grupais. Assim, segundo ele, 
Haverá grupos portadores de neurofibromatose que irão se encontrar para partilhar suas experiências, fazer lobby em torno de questões ligadas as suas doenças, educar seus filhos, refazer seus ambientes familiares, etc. É isto o que eu entendo por biossociabilidade. [...]. Esses grupos terão especialistas médicos, laboratórios, histórias, tradições e uma forte intervenção de agentes protetores para ajudálos a experimentar, partilhar, intervir e 'entender' seu destino (Rabinow, 2002, p. 145).

Pode-se dizer que Rabinow (2002) acerta na previsão. Seja sob forma de grupos de apoio, seja sob forma de redes temáticas na web, conforme estudos anteriores já mencionados neste artigo, muitos esforços de socialização tem sido empreendidos a partir de variáveis biológicas.

\section{0 movimento do asceta se baseia na}

transgressão, na fundação de uma nova

subjetividade, em um universo simbólico

alternativo, tratando-se de uma prática

de liberdade, visando uma dimensão

política e moral.

O conceito de biossociabilidade também aparece em Ortega (2008), porém, tomado de empréstimo de Rabinow, como o próprio autor esclarece em nota de fim de texto 7 . Seu interesse é entender as bioasceses contemporâneas em contraponto com as asceses na Antiguidade. Harpham (1987), citado por Ortega (2008), considera a ascese como uma prática que visa a transformação cultural e hermenêutica. Uma genealogia da ascese foi o eixo em torno do qual Foucault elaborou sua história da subjetividade, conforme Ortega (2008).

O movimento do asceta se baseia na transgressão, na fundação de uma nova subjetividade, em um universo simbólico alternativo, tratandose de uma prática de liberdade, visando uma dimensão política e moral. Portanto, é um fenômeno com foco na alma que pode implicar questões corporais. Já as bioasceses contemporâneas buscam o corpo e a saúde perfeitos, por meio da dietética, do fitness, das cirurgias, do controle de taxas (colesterol, por exemplo), consistindo em práticas nas quais a vontade constrange a liberdade e a espontaneidade, num processo de "assujeitamento" e disciplinamento. Ao contrário das asceses clássicas, as bioasceses visam a uniformidade, a conformação à norma, num processo de somatização da subjetividade.
Para o autor (2008), essa é uma das expressões do conceito de biossociabilidade. Esse conceito abrange a descrição e análise de novas formas de sociabilidade provenientes da interaçãoentrecapital, biotecnologias e a medicina. Para Ortega (2008):

A biossociabilidade é uma forma de sociabilidade apolítica constituída por grupos de interesses privados, não mais reunidos segundo critérios de agrupamentos tradicionais como raça, classe, estamento, orientação política, como acontecia na biopolítica clássica, mas segundo critérios de saúde, performances corporais, doenças específicas, longevidade, entre outros (Ortega, 2008, p. 30).

O autor identifica as bioidentidades como identidades calcadas em procedimentos de cuidados corporais, médicos, higiênicos e estéticos, sendo o corpo a fonte básica de sua identidade. Como Rabinow (2002) faz notar, o conceito de doença é substituído pelo de deficiência na II Guerra Mundial, na Inglaterra, num contexto de avaliação de força de trabalho disponível. O déficit deve ser compensado socialmente, psicologicamente e espacialmente (mulher frente ao homem, negro frente ao branco e deficiente físico frente ao não deficiente físico, etc.), enquanto a doença deve ser tratada. Por consequência, a ocupação com questões particulares de um grupo por parte das bioidentidades sociais faz esquecer ideais sociais mais abrangentes. Tal como assinala Castel, no texto de Ortega (2008), quando a materialidade do biológico informa a experiência identitária, referentes fisicalistas substituem os culturais. Ortega (2008) assinala que, apesar do tom crítico do seu artigo, é inegável que idosos e portadores de deficiência, por exemplo, beneficiaram-se dessa cultura somática, em contraposição à ideologia que estigmatiza a doença e a deformação física. Vejamos, a seguir, o uso que os blogs têm por parte dos deficientes auditivos para que se verifique até que ponto esses conceitos são pertinentes na perspectiva pretendida por este artigo.

\section{Netnografia aplicada à rede de blogs de deficientes auditivos}

$\mathrm{Na}$ medida em que o uso da netnografia no estudo de blogs (Montardo; Passerino, 2006) e combinada à ARS (Montardo, Passerino, 2008; Montardo, 2008) está relatado em estudos anteriores, passaremos à descrição do processo, de acordo com estas etapas. 
Neste estudo, a netnografia é utilizada para a seleção da amostra, via buscadores na web, e a obtenção de dados da amostra da rede (transcrição de textos em tabelas). Foram encontrados 63 blogs, entre os quais, de pessoas com deficiência auditiva em graus variados, de profissionais (educadores, em sua maioria) ou de ambos. Seis autores de blogs portugueses e cinco de blogs brasileiros concordaram em ter seus blogs observados. Destes, 7 blogs são de autores com deficiência auditiva e 4 de profissionais ou de interessados da/na área. O período de análise é de janeiro de 2007 a outubro de 2008.

Além do contato entre os estigmatizados e os "normais" 8 , existe a situação social mista entre os primeiros e os "informados", segundo Goffman (1988). Os informados são pessoas normais que desfrutam da intimidade do estigmatizado, simpatiza com sua condição e são, por isso, aceitos. Exemplos disso são profissionais, como terapeutas, enfermeiras ou, nesse caso, educadores de surdos. Os pais de pessoas com deficiência também são considerados informados. Por essa razão, blogs de informados sobre a deficiência auditiva também fazem parte da rede selecionada, sugerindo a possibilidade de análise da socialização mista.

Desses 11 autores de blogs, seis responderam a um questionário. Chama a atenção que cinco dos respondentes escrevem em mais de um blog. Apenas um dos respondentes afirma atualizar seu blog mais de uma vez por semana, enquanto os outros costumam fazê-lo uma vez por mês, uma vez por semestre ou o fizeram apenas uma vez. Metade dos respondentes afirma comentar em blogs uma vez por mês. Entre os demais, o hábito é mais esparso.

Entre os temas de interesse, tanto para postagens quanto para leitura em blogs, estão questões relativas à deficiência auditiva aliadas a outros de interesse pessoal. Apenas um respondente colocou a deficiência auditiva como único interesse em blogs. As frases a seguir resumem os objetivos dos respondentes em manterem blogs, os quais, segundo afirmam, foram alcançados:

Promover a problemática da surdez, fazendo-a chegar a um maior número de pessoas, sem ser pelos métodos tradicionais de divulgação...(Respondente informado sobre deficiência auditiva).

Ocupação de tempo livre, expressão de sentimentos pessoais sobre a minha doença, divulgar informações sobre a minha doença e a deficiência auditiva, tentar encontrar 'pares'. (Respondente com deficiência auditiva).
Somente um dos respondentes afirma que o blog é a sua única forma de socialização online. Todos os demais afirmam utilizar comunicadores instantâneos, redes sociais e todos os meios "que permitam comunicar com o Mundo" (respondente com deficiência auditiva). Depois de descrita a obtenção de dados dessa rede, importa verificar a sua análise propriamente dita.

\section{ARS e discussão de resultados}

Recuero (2005) fornece um modelo de ARS que contempla o aspecto qualitativo das interações, o qual é constituído de três elementos principais: organização, estrutura e dinâmica. A organização se relaciona à interação social em um grupo, enquanto a estrutura se refere ao resultado das trocas empreendidas no mesmo, em termos de laços sociais e de capital social. Por fim, a dinâmica trata das modificações sofridas por uma rede com o passar do tempo.

\section{A organização e a estrutura da rede serão privilegiadas, uma vez que a dinâmica de redes temáticas sobre pessoas com deficiências tende a ser de cooperação.}

Conforme já se pode perceber na tabela para sistematização de análise dos conteúdos, a organização e a estrutura da rede serão privilegiadas, uma vez que a dinâmica de redes temáticas sobre pessoas com deficiências tende a ser de cooperação. Para a análise da estrutura, pretendendo-se indicar os tipos de conexão que as formam, bem como os tipos de trocas que se estabelecem, aplica-se a adaptação sugerida ao modelo supracitado em um estudo anterior (Montardo; Passerino, 2008), que deduz o tipo de laço social, conforme Granovetter (forte ou fraco) ${ }^{9}$ a partir da análise em conjunto do capital social ${ }^{10}$ implícito na postagem, de acordo com Bertolini e Bravo (2004), e de sua correspondência ou não nos comentários. Por exemplo, se o conteúdo da postagem for de cunho relacional e, em resposta, um comentário for feito correspondendo a essa expectativa, por meio de comentário relacional, tem-se um laço forte. Ao contrário, caso a postagem privilegie um aspecto cognitivo e obtiver como resposta um apelo emocional, configura-se um laço fraco ${ }^{11}$. A Tabela 1 traz considerações sobre a rede selecionada que serão discutidas a seguir: 
TABELA 1 - Resumo da socialização online em rede de deficiência auditiva e informados em blogs.

\begin{tabular}{|c|c|c|c|c|c|c|c|}
\hline Blogs & $\begin{array}{c}N^{\circ} \text { de } \\
\text { postagens em } \\
2007 \text { e } 2008\end{array}$ & $\begin{array}{c}\mathrm{N}^{\circ} \text { de } \\
\text { comentários em } \\
2007 \text { e } 2008\end{array}$ & Tema & $\begin{array}{l}\text { Comentários } \\
\text { de autores } \\
\text { desta rede }\end{array}$ & $\begin{array}{l}\text { Capital social } \\
\text { proposto nas } \\
\text { postagens }\end{array}$ & $\begin{array}{l}\text { Capital social } \\
\text { presente nos } \\
\text { comentários }\end{array}$ & $\begin{array}{l}\text { Laço social } \\
\text { predominante }\end{array}$ \\
\hline 1. Blog Informado 1 & 94 & 63 & $\begin{array}{l}\text { Cursos, congressos, } \\
\text { leis e notícias sobre } \\
\text { assuntos relacionados } \\
\text { à surdez. }\end{array}$ & 0 & Cognitivo & Cognitivo & Forte \\
\hline 2. Blog Informado 2 & 6 & 4 & $\begin{array}{l}\text { Surdez, ensino de } \\
\text { surdos e linguagem } \\
\text { gestual. }\end{array}$ & 1 & Cognitivo & Cognitivo & Forte \\
\hline 3. Blog Informado 3 & 8 & 6 & $\begin{array}{l}\text { Surdez, ensino de } \\
\text { surdos e linguagem } \\
\text { gestual na escola. }\end{array}$ & 0 & Cognitivo & $\begin{array}{l}\text { Relacional/ } \\
\text { Cognitivo* }\end{array}$ & Fraco/Forte \\
\hline 4. Blog Informado 4 & 18 & 52 & $\begin{array}{l}\text { Poemas e parábolas } \\
\text { de cunho religioso, } \\
\text { pouca informação } \\
\text { sobre surdez. }\end{array}$ & 1 & Relacional & Relacional & Forte \\
\hline 5. $\mathrm{Blog} \mathrm{DA}^{12} 1$ & 34 & 35 & $\begin{array}{l}\text { Sobre a experiência } \\
\text { de ouvir após o } \\
\text { Implante Coclear. }\end{array}$ & 2 & Relacional & Relacional & Forte \\
\hline 6. Blog DA 2 & 10 & 1 & $\begin{array}{l}\text { Reflexões filosóficas, } \\
\text { parábolas e poemas. }\end{array}$ & 0 & Relacional & Cognitivo & Fraco \\
\hline 7. Blog DA 3 & 41 & 76 & $\begin{array}{l}\text { Vida na universidade, } \\
\text { assuntos em geral, } \\
\text { posicionamento } \\
\text { quanto à Cultura dos } \\
\text { Surdos. }\end{array}$ & 4 & Relacional & Relacional & Forte \\
\hline 8. Blog DA 4 & 1 & 1 & $\begin{array}{l}\text { Comentário sobre um } \\
\text { filme. }\end{array}$ & 0 & Relacional & Cognitivo & Fraco \\
\hline 9. Blog DA 5 & 2 & 2 & $\begin{array}{l}\text { Currículo e datas de } \\
\text { exposição de Arte. }\end{array}$ & 0 & Cognitivo & Cognitivo & Forte \\
\hline 10. Blog DA 6 & 2 & 2 & $\begin{array}{l}\text { Relato pessoal sobre } \\
\text { surdez, leis para } \\
\text { Educação de surdos. }\end{array}$ & 0 & $\begin{array}{l}\text { Relacional/ } \\
\text { Cognitivo }\end{array}$ & $\begin{array}{l}\text { Relacional/ } \\
\text { Cognitivo* }\end{array}$ & Forte \\
\hline 11. Blog DA 7 & 14 & 1 & $\begin{array}{l}\text { Vídeos ligados a } \\
\text { assunto gerais, figuras } \\
\text { ligadas à surdez. } \\
\text { Ex: alfabeto digital. }\end{array}$ & 0 & Cognitivo & Cognitivo & Forte \\
\hline
\end{tabular}

FONTE: Elaborado pela autora.

* Não há predomínio de um sobre o outro, havendo o mesmo número de ocorrência para ambos.

Como se percebe, esta rede é bastante fragmentada, uma vez que no blogroll de nenhum dos blogs analisados há links para outros da mesma amostra. Da mesma forma, não se encontram links nas postagens apontando para outros blogs. No entanto, é na troca de poucos comentários de duas autoras de blogs DA e de comentários de uma delas às postagens de informados que garantem o frágil aspecto de rede entre alguns desses blogs.

Uma constatação decorrente disso é que a maioria desses blogs aparece como unidades iso- ladas de uma rede temática maior, pelo menos a partir de um ponto de vista quantitativo, baseado em número de links. Uma hipótese é que muitos desses autores escrevem em mais de um blog, o que pode acarretar certa dispersão na atualização de postagens e comentários. Entretanto, em questionário um autor de blog respondeu que, apesar de não receber muitos comentários, seu blog é bastante lido.

Quanto aos temas tratados, os blogs de DA não se restringem à deficiência auditiva, mas combinam-se a outros, ligados ao cotidiano. 
Conforme já foi posto, o Implante Coclear é uma constante quando o tema é a deficiência auditiva e, consigo, revela outros aspectos da comunidade Surda, como mostra os trechos de postagens a seguir.

As minhas conquistas sonoras são tão capazes de esmagar em absoluto os críticos em relação ao Implante Coclear, por isso xô! Escutar é extraordinário! Ainda mais uma benção em discriminar algumas das palavras e melhor do que os sonhos só mesmo a realidade (DA 1).

DA 3 testemunha, de acordo com Moura (2000) e com Goggin e Newell (2003), que a comunidade de surdos não é homogênea, que cada surdo tem sonhos, nível cultural e recursos técnicos diferentes. Além disso, ela, que não usa o Implante Coclear, defende o direito de cada surdo em fazer suas próprias escolhas, sem depender das opiniões dos porta-vozes, ou "relações públicas" da cultura surda, como ela os chama. "Ou seja, quer que usemos prótese auditiva quer optemos pelo implante coclear ou que desistamos dessas possibilidades, o respeito pela opção individual é, e deve ser, prevalecido". (DA 3). É importante destacar que não foi localizada na amostra, em postagens ou comentários, nenhuma posição contra esse Implante, o que deve ser uma posição dominante na comunidade de surdos.

Não só profissionais formam a categoria de informados dessa rede. Porém, os pais de DA não compõem essa amostra, tal como se percebeu em redes estudadas anteriormente.

\section{Considerações finais}

A análise desta rede permite observar que a biossociabilidade online de DA e de informados sobre o tema existe. No entanto, pode-se falar apenas em redes temática na web quanto aos blogs de profissionais, no sentido de se restringirem ao tema da educação da linguagem dos surdos. Entre os próprios, a deficiência auditiva convive com outros comentários do cotidiano. Nota-se que o contato entre os DA e os informados via blogs é restrito, resumindo-se ao agradecimento pelo interesse na temática dos primeiros em relação aos últimos. Entre informados, sejam blogueiros ou leitores de blogs, as trocas são quase que exclusivamente de capital social cognitivo.

Percebe-se uma identificação entre a oscilação de identificações em situações sociais mistas, prevista por Goffman (1988), e as experimenta- das pelos ascetas, por um lado, e pelos bioascetas, por outro, conforme Ortega (2008). Para o estigmatizado, a associação ou distanciamento com relação aos seus iguais pode provocar essas oscilações, numa alternância entre a decisão de se assumir como surdo ou na adoção dos valores da cultura ouvinte. Assim como o asceta, alguns deficientes auditivos buscam um deslocamento de subjetividade, que visa a um modo alternativo de vida, um movimento pela liberdade de passarem a ouvir, por meio de próteses e implantes, como revelam algumas citações de blogueiros com deficiência auditiva. Porém, tal qual o bioasceta, estas escolhas provém de decisões pessoais, individuais, e, por isso, apolíticas, de acordo com os autores consultados, e exigem certa disciplina para o sucesso das intervenções cirúrgicas (fazer reajustes necessários, praticar a identificação de sons, etc.).

Em parte, a fragmentação da rede se deve à ausência dos arautos da Cultura Surda na web, pelo menos entre os blogs da amostra. Ao que tudo indica, por uma questão ideológica, conforme já posto, estes devem se comunicar predominantemente pela LS e não necessariamente conheçam a Língua Portuguesa, o que os impossibilitaria de usar a web.

A IS, nesse caso, pode ser identificada nos blogs de informados voltados para informados, que tem por consequência a inclusão dos deficientes auditivos, e nos relatos pertinentes à deficiência auditiva feitos pelos DA para os mesmos e para os informados.

\section{REFERÊNCIAS}

AMARAL, Adriana; MONTARDO, Sandra Portella; RECUERO, Raquel. Blogs.com: estudos sobre blogs e comunicação. São Paulo: Momento Editorial, 2009. Disponível em: <http://www.sobreblogs.com.br>. Acesso em: 01 fev. 2009.

BERTOLINI, Sandra; BRAVO, Giácomo. Social Capital, a Multidimensional Concept. 2004. Disponível em: <http://www. ex.ac.uk/shipss/politics/research/socialcapital/other/bertolini.pdf $>$. Acesso em 10 out. 2008.

BLOOD, Rebecca. Weblogs: a history and perspective. 2000. Disponível em: <http://www.rebeccablood.net/essays/weblog history.html>. Acesso em: 30 jul. 2008.

BRUNS, Axel; JACOBS, Joanne. Uses of blogs. New York: Peter Lang, 2007.

GOFFMAN, Erving. Estigma: notas sobre a manipulação da identidade deteriorada. 4. ed. Rio de Janeiro: Guanabara, 1988.

GOGGIN, Gerard; NEWELL, Christopher. Digital disability. The social construction of disability in new media. Maryland: Rowman \& Littlefield, 2003. 
GRANOVETTER, Mark. The strenght of weak ties: a network theory revisited. In: Sociological Theory, v. 1, 1983. p. 201-233.

La fuerza de los vínculos débiles. 1974. Disponível em: <http://www.ucm.es/info/pecar/Articulos/GRANOVETTER 2.pdf>. Acesso em: 30 jan. 2009.

MONTARDO, Sandra Portella. Fotos que fazem falar: desafios metodológicos para análise de redes temáticas em fotologs. In: Revista Famecos, Porto Alegre, n. 37, p. 75-84, dez. 2008. Disponível em: <http://www.pucrs.br/famecos/pos>. Acesso em: 2 fev. 2009.

MONTARDO, Sandra Portella; PASSERINO, Liliana. Espelhos quebrados no ciberespaço: implicações de redes temáticas em blogs na Análise de Redes Sociais (ARS). Anais do 17ํㅜㅇ Encontro da Associação Nacional de Programas de Pós-Graduação de Comunicação (Compós). São Paulo, UNIP, 2008. Disponível em: <http://www.compos.org.br>. Acesso em: 10 out. 2008.

. Inclusão social via acessibilidade digital: proposta de inclusão digital para Pessoas com Necessidades Especiais (PNE). In: E-Compós, v. 8, abr. 2007. Disponível em: $<$ http://www.compos.org.br/ecompos/adm/documentos/ ecompos08_abril2007_passerino_montardo.pdf $>$.Acessoem: 10 out. 2008.

Estudo dos blogs a partir da netnografia: possibilidades e limitações. In: Renote, Porto Alegre: UFRGS, v. 4, n. 2, dez. 2006. Disponível em: <http://www.cinted.ufrgs. br/renote/dez2006/artigosrenote/25065.pdf $>$. Acesso em: 10 out. 2008.

MOURA, Maria Cecília. O surdo: caminhos para uma nova identidade. São Paulo: Revinter, 2000.

ORTEGA, Francisco. Do corpo submetido à submissão do corpo. In: ORTEGA, F. O corpo incerto. Corporeidade, tecnologias médicas e cultura contemporânea. Rio de Janeiro: Garamond, 2008

RABINOW, Paul. Artificialidade e iluminismo: da biossociologia à biossociabilidade. In: RABINOW, P. Antropologia da razão. Rio de Janeiro: Relume Dumará, 2002.

RECUERO, Raquel. Comunidades virtuais em redes sociais: uma proposta de estudo. In: E-Compós, Brasília, v. 4, dez. 2005. Acesso em: 5 jan. 2009.

REDONDO, Maria Cristina; CARVALHO, Josefina Martins. Cadernos da TV Escola. Deficiência auditiva. Brasília: MEC, Secretaria de Educação a Distância, 2000.

\section{NOTAS}

1 Trabalho apresentado ao Grupo de Trabalho "Comunicação e Cibercultura", do XVIII Encontro da Compós, na PUC-MG, Belo Horizonte, MG, em junho de 2009.

2 Sobre IS, ver Montardo e Passerino (2007).

3 Projeto contemplado com o Edital MCT/CNPq 14/2008 Universal.

4 Existem surdos-mudos e surdos-falantes, conforme Moura (2000).

5 Para Goffman (1988), há três tipos de estigma: deformidades físicas, culpas de caráter individual (prisão, vício, prostituição, etc.) e tribais (raça, nação e religião).

6 É um dispositivo que pode ser embutido por cirurgiões atrás do ouvido no crânio. Eletrodos passam pelo dispositivo para dentro do ouvido interno ou cóclea, permitindo a estimulação de suas fibras neurais, permitindo a captação de sons para o seu usuário. (Goggin; Newell, 2003).

7 Segundo Ortega (2008), o termo biossociabilidade em Rabinow provem de uma tradução de "Artificiality and Enlightenment: From Sociobiology to Biosociability" feita em 1999. No original, segundo nota em Rabinow (2002), o artigo foi publicado em Janathan Crary (Ed.), Zone 6: Incorporations, Cambridge, MIT Press, 1992.

8 No decorrer do artigo, utilizar-se-á a palavra "normal" tal qual feito por Goffman (1988): pessoa não estigmatizada na relação social considerada, ou seja, a pessoa que não tem deficiência auditiva.

9 Para Granovetter (1974), laços fortes são aqueles que indicam uma relação linear entre tempo, intensidade emocional, intimidade (confiança mútua) e serviços recíprocos entre os atores de um mesmo cluster, enquanto que os laços fracos se caracterizam por contatos irregulares (em freqüência e em intensidade) que ocorrem nas relações sociais. Justamente por isso, os laços fracos constituem fonte alternativa de informações e, com isso, de provável mobilidade dentro da sociedade.

${ }^{10}$ Para Bertolini e Bravo (2004), citados por Recuero (2005), existem cinco tipos de capital social: relacional, normativo, cognitivo, confiança no ambiente social e institucional.

${ }^{11}$ É importante lembrar que, para Granovetter (1974, 1983), um laço fraco não é inferior a um laço forte em termos de socialização.

12 Deficiente auditivo(a). 